\title{
DizerOUmostrar, em Wittgenstein, e A Tetralogia da Incomunicabilidade, de Antonioni ${ }^{1}$
}

\author{
ANA PAULA GRILLO EL-JAICK
}

Ana Paula Grillo El-Jaick é professora Adjunta da Faculdade de Letras da Universidade Federal de Juiz de Fora (UFJF). Pós-doutora com pesquisa no Laboratório Arquivos do Sujeito (LAS) da Universidade Federal Fluminense (UFF). Doutora em Estudos da Linguagem pela Pontifícia Universidade Católica do Rio de Janeiro (2009), tendo desenvolvido estágio doutoral na École Normale Supérieure (Paris). Possui Mestrado em Letras também pela Pontifícia Universidade Católica do Rio de Janeiro (2005), graduação em Letras (2005) e em Direito (1999) pela Universidade Federal Fluminense. Tem experiência na área de Linguística, com ênfase em Filosofia da Linguagem. Atualmente, atua como pesquisadora no Grupo de Pesquisa em Língua(gem) e Sociedade (GRUPELS) da UFJF, investigando o conceito de linguagem como forma de vida tal como formulado nos escritos do Wittgenstein maduro.

\footnotetext{
${ }^{1}$ Uma versão preliminar deste artigo foi publicada nos ANAIS do IV Simpósio Internacional sobre Análise do Discurso (IV SIAD). 
No amor, assim como em quase todas as atividades humanas, o entendimento cordial é o resultado de um mal-entendido. É nesse mal-entendido que está o prazer. O homem grita: "Oh, meu anjo". A mulher arrulha: "Mamãe! Mamãe!" E esses dois imbecis ficam convencidos de que pensam em uníssono. - O abismo insuperável que causa a incomunicabilidade ainda não foi transposto.

Charles Baudelaire

\section{- RESUMO}

Os filmes "A Aventura" (1960), "A Noite" (1961) e "O Eclipse" (1962), de Michelangelo Antonioni, não foram premeditadamente concebidos como uma trilogia, mas, ainda que à revelia do diretor, são comumente agrupados como a "Trilogia da Incomunicabilidade" - a qual alguns críticos ainda incluem "O deserto vermelho" (1964). Analisarei esse (pretenso?) discurso da incomunicabilidade a partir do notório aforismo de L. Wittgenstein com que o filósofo vienense termina seu Tractatus Logico-Philosoficus: "Sobre aquilo de que não se pode falar, deve-se calar" (TLP §7) e, também, a partir da perspectiva de linguagem da segunda fase de seu pensamento, aquele expresso em suas "Investigações Filosóficas", quando a linguagem passa a ser entendida por Wittgenstein como uma prática humana, como forma de vida. Assim, explorando o paradoxo de se comunicar a incomunicabilidade, este texto não chega a "resultados finais"; antes, abre-se para, pelo menos, dois paradoxos. Por fim, entendemos que tais paradoxos tendem a mostrar que, se é possível comunicar a incomunicabilidade, isso seria menos o triunfo da comunicação e mais um reconhecimento dos limites da linguagem.

\section{PALAVRAS-CAVE}

Wittgenstein, Antonioni, formas de vida, trilogia da incomunicabilidade.

\section{- ABSTRACT}

Michelangelo Antonioni's "The Adventure" (1960), "The Night" (1961) and "Eclipse" (1962) were not premeditatedly conceived as a trilogy but, despite Antonioni desire, they are commonly grouped as a "trilogy on modernity and its discontents" - which some critics still include "Red Desert" (1964). I will analyze this discourse of modernity / incommunicability from L. Wittgenstein's notorious aphorism with which the Viennese philosopher ends his "Tractatus Logico-Philosoficus": "What we cannot speak about we must pass over in silence" (TLP §7) And also from the perspective of language of the second phase of his thought, expressed in his "Philosophical Investigations", when language comes to be understood by Wittgenstein as a human practice, as a life-form. Thus, exploring the paradox of communicating incommunicability, this text does not reach "final results"; rather, it opens up to, at least, two paradoxes. Finally, we understand that such paradoxes tend to show that, if it is possible to communicate incommunicability, this would be less the triumph of communication and more the recognition of the limits of language.

\section{- KEYWORDS}

Wittgenstein, Antonioni, life-form, trilogy on modernity and its discontents. 


\section{O filme/O texto - sem cortes:}

O cineasta italiano Pier Paolo Pasolini, em seu conhecido artigo "Cinema de poesia", defende a tese de que, apesar de prevalecer a natureza comunicativa da prosa na breve tradição da história do cinema, vínhamos testemunhando a mudança dessa trajetória, que então se dirige, também, para um cinema de poesia (1970[1965], p.22-33). Assim, Pasolini dá exemplos concretos da instauração no cinema de uma possível tradição do que ele chamou de "língua técnica da poesia", ou "língua do cinema de poesia" (Idem, p.36): "Como exemplos concretos de tudo isto, citarei Antonioni, Bertolucci e Godard - mas também poderia acrescentar Rocha do Brasil, ou Forman da Checoslováquia, e naturalmente muitíssimos mais" (Idem, p.29).1

Não é à toa que Michelangelo Antonioni foi o primeiro nome citado por seu compatriota. Afinal, sua técnica é trabalhada para o bem do poético. O diretor conduz o espectador com uma língua especial, de forma a dar a ver o interior de seus personagens. Conforme continua Pasolini em seu texto: na "língua de poesia cinematográfica" o "verdadeiro protagonista é o estilo. A câmera, por conseguinte, é notada, e por bons motivos" (Idem, p.38).

A poesia cinematográfica de Antonioni, de fato, tem o traço de seu estilo. Notamos a câmera e a montagem como versos de um poema - seus filmes não se fundamentam na natureza comunicativa da prosa. Vemos poesia: sua câmera corta estrofes, sua montagem pictórica edita versos, seu ritmo é o de um poema. Nas palavras do próprio Antonioni:

Enquanto para meu caríssimo amigo Wim Wenders [cineasta que aju-
dou Antonioni a filmar "Além das Nuvens", seu penúltimo filme (1995),
depois que este sofreu um acidente vascular-cerebral que o deixou
paralisado do lado direito e quase completamente impossibilitado de
falar] filmar é uma diversão incrível, para mim, filmar é quase um sofri-
mento por ter de enfrentar continuamente esta obsessão das soluções
técnicas que, ao mesmo tempo, têm de ser poéticas. É algo que me
cansa muito (O OLHAR, 2001, 49:30).

Filmar é penoso porque o poético é, também, técnico - os dramas encenados por Antonioni são, segundo ele mesmo, igualmente psicológicos e plásticos (ANTONIONI apud BARTHES, 1980, p.1). As histórias de seus filmes são aparentemente banais; porém, sua forma tenta desvelar a própria existência humana. Nas palavras do próprio diretor: "Nas minhas histórias [...] sempre acontecem coisas mais interiores que exteriores" (O OLHAR, 2001, 21:14).

$O$ escritor e diretor francês Alain Robbe-Grillet, na homenagem televisiva "Dear Antonioni", transmitida pelos canais de televisão RAI e BBC nos anos 1990, tem uma boa análise sobre como Antonioni encena estes acontecimentos interiores:

A imagem mais tradicional em Antonioni não é tradicional, mas ela é clássica em seus filmes: a câmera fixa um personagem, o personagem não está centralizado, em geral, ele está descentralizado, o que

\footnotetext{
$\overline{2}$ Todas as traduções dessa edição são de minha autoria.
} 
já é uma característica importante, e o personagem olha para além. Quer dizer que há um primeiro ponto de vista, aquele da câmera, e um segundo ponto de vista, aquele do personagem que olha "para fora". E no cinema tradicional e clássico ele olharia alguma coisa e a gente mostraria num ângulo reverso aquilo que este olhar vê. Aqui, ao contrário, não: permanece em aberto. $O$ espectador que vê esta imagem tem duas possibilidades: pensar que ele olha alguma coisa e que essa coisa é importante, mas que a gente não sabe o que é; ou talvez que, na verdade, ele não olha nada: ele olha o mundo, simplesmente. Quer dizer que, no final das contas, o olhar se volta para ele próprio (DEAR, 1990, 21:56).

Os filmes "A Aventura" (1960), "A Noite" (1961) e "O Eclipse" (1962) não foram premeditadamente concebidos como uma trilogia, mas os críticos veem aí uma certa unidade, de modo que os três filmes acabariam por se complementar - e, assim, compõem essa que ficou conhecida como a "Trilogia da Incomunicabilidade", ainda que o próprio diretor não reconheça tal nomenclatura. Antonioni sustenta não ter qualquer apreço pela falta de comunicação. Ele afirma que seus personagens buscam se comunicar entre si. Contudo, não é preciso muita audácia para concluir que essa busca é infrutífera - é um desejo sempre frustrado. No fim, o que há, o que Antonioni encena é essa incompletude: os três filmes, mais "O deserto vermelho" (1964), enquadram casais unidos pela falta de comunicação. ${ }^{3}$

O desagrado de Antonioni frente ao título trilogia da incomunicabilidade se deve à sua pertinácia em enfatizar que, se seus personagens não se comunicam, eles tampouco estão felizes com isso. Dessa maneira, os personagens de seus filmes estariam interligados - ainda que por uma linha tênue, frágil. Entretanto, vemos que os protagonistas dos três filmes são casais que só se fazem assim nomear porque se apresentam aos pares - mas são personagens, sobretudo, solitários.

"A Aventura" nasceu de um fato ocorrido com Antonioni e Monica Vitti, atriz com quem então era casado, quando partem para uma ilha, com amigos, para um passeio. Lá, têm uma discussão - "normal” de casal, conforme conta o diretor. Vitti sai pela ilha e some por uma hora e meia. Quando se reencontram, Antonioni the diz: "Acho que tenho uma ideia. Aconteceu algo. Precisamos conversar". A conversa durou dois anos e semeou o roteiro de "A Aventura", coassinado por Tonino Guerra.

No filme, Anna (Lea Massari) desaparece depois de uma discussão com seu namorado Sandro (Gabriele Ferzetti). "A Aventura" é a própria procura por Anna; o que acontece nessa procura - principalmente entre Sandro e a melhor amiga de Anna, Claudia (Monica Vitti). Este fio de argumento - sumiço e busca envolvendo Anna, Sandro e Claudia - é o que conduz e encena aquela que é a obsessão do diretor: a problemática existencial.

Em outras mãos, esse filme poderia facilmente se tornar um thriller policial e, de fato, Monica Vitti conta em entrevista como, em sua busca para encontrar algum produtor que financiasse "A Aventura", Antonioni ouviu: "A mulher tem de ser encontrada!". Todavia, o diretor não queria fazer um filme de ação, senão exatamente o oposto disso. Assim, ao contrário do que desejavam alguns possíveis pro-

${ }^{3}$ Seguirei aqui os críticos que defendem haver, na verdade, uma tetralogia ao incluírem este último filme, "O deserto vermelho" (1964). 
dutores do filme, a mulher não é encontrada. O que aconteceu com ela? Antonioni ironizou seu fim inconcluso: "Me disseram que ela se matou, mas não creio" (ANTONIONI apud VEJA, 2012, p.2).

Se há ação em "A Aventura", esta é para dentro: filma-se a ausência - como a da personagem Anna, e o que acontece depois disso. Antonioni encena a falta - e a solidão que essa falta, essa sede que nos move faz surgir. Sandro, por exemplo, sofre daquilo que Antonioni qualificou de malattia dei sentimenti [doença dos sentimentos] - vive numa constante confusão erótica e profissional. Profissionalmente, é um arquiteto frustrado. Amorosamente, no curso pela busca de sua namorada Anna, acaba por se envolver com Claudia, e, na mesma noite que diz amá-la, conquista uma desconhecida numa festa. A cena final é contundente: flagrado por Claudia, Sandro termina em lágrimas - até que a câmera flagra a mão de Claudia, que se levanta, diligentemente, não apenas para perdoar, mas, principalmente, para consolar Sandro (de suas palavras vazias? de suas pulsões incontroláveis? de sua condição, finalmente, de homem solitário? de seu oco?). Assim, frustrando uma aposta por um filme policial, "A Aventura" não se pergunta sobre o paradeiro de Anna, mas "Por que o amor é tão estranhamente inexplicável?" (CHATMAN; DUNCAN, 2008, p.10). Afinal, a atitude de Sandro não está no âmbito da aprovação ou condenação, mas da piedade. Antonioni assim definiu "A Aventura":

\footnotetext{
Os personagens do filme vivem uma aventura emocional - ela implica a morte e o nascimento de um amor. Uma aventura psicológica e moral que os faz ir ao encontro das convenções estabelecidas e dos critérios de um mundo de agora em diante excedido (ANTONIONI apud CHATMAN; DUNCAN, 2008, p.33).
}

O crítico R. A. Oliveira vê nas ilhas de Lisca Bianca, onde se passam as cenas iniciais do filme, uma metáfora das relações humanas: pequenas ilhas, extremamente próximas, de modo que uma ilha vê as outras ilhas, mas permanecem separadas umas das outras: ilhas (OLIVEIRA, 2008. p.3). O isolamento da ilha chegou a prejudicar as filmagens em uma ocasião em que o mar se mostrou muito revolto, o que fez com que a equipe ficasse ilhada por uma noite e um dia inteiros presos naquela ilha então inacessível, sem comida, sem nada, porque tudo, as provisões ficaram num barco maior, que não tinha como se aproximar da ilha (ANTONIONI, 1966, 13:15). E esse não foi o único percalço nas filmagens. Dentre outros, os técnicos começaram uma greve para protestar pelas más condições de trabalho e atraso no pagamento (CHATMAN; DUCAN, 2008, p.29).

Monica Vitti dá seu depoimento sobre a sofrida noite em que o filme foi vaiado no Festival de Cannes, de 1960 (neste ano o vencedor foi "A Doce Vida", de F. Fellini). Vitti conta como o público logo perdeu o interesse pelo filme e riu o tempo inteiro, desde o início, desde os créditos, nas cenas que haviam sido difíceis para toda a equipe, nas cenas que tinham sido penosas fazer. No dia seguinte, no entanto, ao saírem do lobby do hotel, encontraram uma lista de vários nomes importantes do mundo do cinema - diretores (italianos e estrangeiros), jornalistas, críticos, escritores. Essa lista era encabeçada por Roberto Rosselini e precedia por algumas palavras: "Ontem à noite vimos o mais belo filme apresentado no Festival". 
Finalmente, o filme figura entre os vinte melhores filmes da história da influente revista "Sight and Sound" (CHATMAN; DUNCAN, 2008, p.30)

O segundo filme da trilogia, "A Noite", traz Lidia (Jeanne Moureau) e Giovanni (Marcello Mastroianni) como o casal protagonista. A noite se passa numa festa na casa de um milionário que convidou o escritor Giovanni e sua esposa segundo ela, porque todo milionário procura seu intelectual. Como nos outros filmes da trilogia, recorre a ideia de solidão, tédio, inquietude sobre o que fazer. De fato, é significativo que a primeira fala do filme é a reincidente pergunta "O que devo fazer? O que devo fazer?", proferida por um amigo do casal, amigo este que está hospitalizado e faz a pergunta ao enfermeiro que lhe aplica morfina (A NOITE, 1961, 3:00).

Como nos outros dois filmes, recorre ao menos uma cena em que os personagens, num meio urbano, contemplam as mudanças (erradas) operadas na arquitetura da cidade, no urbanismo moderno como um destino sobre o qual não temos qualquer poder de intervenção, de modo que só nos resta reconhecer a impossibilidade de se criar algo de sólido, que sobreviva às mudanças. Essa impossibilidade de conter a mudança também atinge as relações humanas. As relações também mudam, já que não são sólidas. Lidia flerta com um desconhecido na festa, ainda que não consiga consumar a traição. Giovanni flerta com a filha do milionário, a bela Valentina (Monica Vitti). Entretanto, não há ciúme - Lidia diz não amar mais Giovanni. Ela sente mais é pena dele por sua infelicidade. Como em "A Aventura", também em "A Noite" há um diálogo em que o personagem masculino é confrontado com a palavra sacrifício pelo bem do relacionamento e reage: mas por que se sacrificar? (Aliás, caberia para um outro estudo uma análise do egoísmo desses personagens masculinos, deixando mesmo em alguns momentos seu narcisismo esbarrar em certo machismo.)

Em "O Eclipse", a jovem tradutora Vittoria (Monica Vitti) se envolve com Piero (Alain Delon), um operador da bolsa de valores, depois que ela rompeu um relacionamento com Riccardo (Francisco Rabal). Desses três filmes, "O Eclipse" parece colocar luz em outros momentos de incomunicabilidade para além da dificuldade entre Vittoria e seu ex, Riccardo, e seu pretendente Piero. De fato, as cenas que têm como cenário a bolsa de valores são bastante significativas: em vez do acostumado silêncio de Antonioni, temos gritaria - mas uma gritaria em que não se entende uma palavra do que é berrado. O incomunicável, aqui, beira o animalesco, o grotesco: há urros, não há texto propriamente ${ }^{4}$. Este é o terceiro casal da trilogia da incomunicabilidade; o terceiro casal que se comunica pelo incomunicável. "O Eclipse" eclipsa: não há realmente um eclipse no filme. Novamente, podemos dizer que esse obscurecimento ocorre dentro dos personagens - como uma ausência, um afastamento de sentimentos. Logo no início do filme, quando Vittoria termina seu relacionamento com Riccardo, vemos ao fundo uma caixa d'água em forma de cogumelo nuclear, uma possível referência à guerra fria e à ameaça nuclear. Antonioni escreve sobre o filme:

1962. Em Florença, para ver e filmar o eclipse do sol. Frio repentino. Um silêncio diferente de todos os outros silêncios. Luz terrestre, dife-

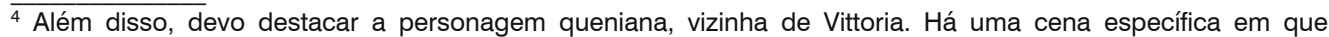
poderíamos discutir a incomunicabilidade entre culturas: primeiramente, Vittoria e uma terceira vizinha imitam os negros de uma forma bastante preconceituosa, até que a vizinha queniana grita: "Parem de imitar os negros". Contudo, pouco depois essa mesma vizinha queniana chama os negros de "macacos" (O ECLIPE, 1962, 34:37).
} 
rente de todas as outras luzes. E, então, escuridão. Imobilidade total. Tudo o que consigo pensar é que, durante o eclipse, os sentimentos também param. É uma ideia que tem vagamente a ver com o filme que estava preparando, mais uma sensação que uma ideia, mas que já define o filme, se bem que este ainda esteja longe de estar definido [...] Deveria ter posto, nos créditos iniciais de "O Eclipse", estes dois versos de Dylan Thomas: "Alguma certeza deve porém existir, se não a de amar bem, pelo menos a de não amar (MIGELANGELO, 2001, $50: 55)$.

Por fim, em "O Deserto Vermelho" reconhecemos regularidades com os outros três, ainda que este pareça ser mais político: há, por exemplo, a questão do meio ambiente de forma explícita; e pelo menos um diálogo em que Giuliana (Monica Vitti) pergunta a Corrado (Richard Harris), amigo de seu marido Ugo (Carlo Chionetti) mas que se apaixona por Giuliana no instante em que a vê, se ele é de direita ou de esquerda (enquanto vemos ao fundo uma árvore lilás). "O Deserto Vermelho" parece arrebentar a corda que os outros filmes também tocam: se em todos acontecem triângulos amorosos, aqui três casais compartilham uma cama, num suingue simulado; se nos outros filmes experenciamos a solidão humana, aqui Giuliana admite que o acidente de carro de que vem se recuperando foi, na verdade, tentativa de suicídio.

Nos quatro filmes temos o inverso do happy end - o cineasta/poeta não termina suas películas com um grand finale. No final, sim, ainda que corra o risco de ser cafona, ou ridículo, vamos acabar falando de amor. Vou acabar analisando quatro cenas cujos diálogos, a meu ver, são exemplares do incomunicável atribuído ao diretor.

A primeira fala é de "A Aventura":

Anna: Sandro, um mês é muito tempo. Eu estava acostumada a ficar sem você.

Sandro: O mal-estar de sempre. Logo passa.

Anna: Mais forte que o normal.

Sandro: Só vai demorar um pouco mais para passar.

Anna: Mas eu creio que deveríamos falar sobre isso. Ou acha que também não conseguiremos nos entender.

Sandro: Teremos muito tempo para falar. Vamos nos casar. Quer mais tempo?

Anna: Casar neste caso não significaria nada. [...]

Sandro: Mas para que ficar aqui discutindo e falando? As palavras, acredite em mim, servem cada vez menos... Confundem. (A

AVENTURA, 1960, 23:00)

A segunda fala é de "A Noite": Valentina confessa a Giovanni: "Todas as vezes que tentei me comunicar com alguém o amor foi embora" (A NOITE, 1961, 1:36:24). A terceira fala é de "O Eclipse": "Gostaria de saber se você se entendia 
com seu namorado anterior". "Enquanto houve amor, houve entendimento. Nada havia a entender." Finalmente, em "O Deserto Vermelho" a incomunicabilidade chega à carne, gravada que está no próprio corpo: "Não sou solteira. Mas, às vezes, me sinto... separada. Não, não do meu marido, não. Os corpos... estão... separados. Se você me beliscar, eu não vou sentir. O que eu estava dizendo? Ah, sim! Eu estive doente, mas não devo pensar nisso. Quer dizer, eu devo pensar que tudo que acontece comigo é minha vida. Isso." (1h48min23s).

Os casais não se entendem. De nada adianta falar, posto que as palavras são inúteis. Elas não trazem clareza, mas só mais confusão. Para amar é preciso prescindir da linguagem verbal. $\mathrm{O}$ amor tem de ser sem palavras; o amor é inefável. Ele prescinde de entendimento porque está fora do campo do inteligível. As palavras não levam ao entendimento - mas ao contrário disso.

Investigo o comunicável e o incomunicável a partir do notório aforismo de L. Wittgenstein com que o filósofo vienense termina seu "Tractatus Logico-Philosoficus"5: "Sobre aquilo de que não se pode falar, deve-se calar" (TLP §7). Para Antonioni, o amor é uma dessas coisas sobre as quais não se pode falar - deve-se calar porque o entendimento só se dá sem palavras; deve-se calar porque não há o que entender se não for sem palavras. Para o Wittgenstein do "Tractatus", não se pode falar daquilo que não se pode ajuizar como verdadeiro ou falso empiricamente; ou seja, não se pode falar daquilo que não constitui uma proposição que representa o real, a totalidade dos fatos que é o mundo (TLP § 1.1). Em outras palavras, apenas as proposições que representam o mundo podem ser verificadas - e, portanto, ditas. Já as proposições metafísicas, que não constituem uma representação do real, que não apontam para um fato no mundo, devem ser caladas - pois são absurdas, pois são inverificáveis.

Para o assim chamado primeiro Wittgenstein, comunicamos apenas na medida em que denotamos coisas no mundo; representamos o mundo por uma linguagem que espelha o real. Segundo ele, o que está fora do mundo pertence à esfera do incomunicável - as proposições éticas, estéticas, não podem ser ditas, só podem ser mostradas.

Ao que parece, em Antonioni, o amor estaria aí: são proposições metafísicas, absurdas, inverificáveis, impossíveis - logo, indizíveis, inefáveis, incomunicáveis. Antonioni é o mestre do tempo morto, "que consiste em deixar a câmera filmando quando qualquer outro diretor teria cortado" (CHATMAN; DUNCAN, 2008, p.23). Aquele tempo aparentemente sem importância, aquela cena destinada à mera ligação entre cenas - esse tempo morto de Antonioni é esticado de modo a dar vida e outro significado a seus filmes/poemas. Antonioni explica:

Quando a cena principal acaba, há momentos menos importantes; me parece útil mostrar o personagem nesses momentos, de costas ou de frente, dando o tom a um gesto, uma atitude, pois eles servem para clarificar tudo que acaba de acontecer, bem como o que resta no interior dos personagens (ANTONIONI apud CHATMAN; DUNCAN, 2008, p.23).

\footnotetext{
${ }_{5}$ Doravante TLP.
} 
Assim, seu tempo se expande - e prolonga a incomunicabilidade desses personagens (apesar de tentarem arduamente se comunicar). Personagens, aqui, conforme ressalvam Chatman e Duncan, quer se referir mais às reações dos atores - no momento em que saem de seus papéis e reencontram a realidade (CHATMAN; DUNCAN, 2008, p.23).

Os filmes de Antonioni também são como uma forma de vida - com seu tempo morto, acasos e mudanças. A cena se estica como se houvesse um pós-cena - mas é que o corte é sempre adiante, depois, como a vida que segue. O diálogo termina, mas as personagens ainda estão lá. Antonioni explica:

Já nessa época [1950, quando filmou seu primeiro longa-metragem de ficção, "Crimes d'Alma"] eu precisava ver os personagens, mesmo em seus gestos mais simples depois de tudo ter sido dito, depois de exauridos os diálogos e quando só restassem as consequências do que havia ocorrido na alma de cada um (ANTONIONI, 1966, 13:15).

Essa introspecção parece ser uma recorrência na cinematografia de Antonioni. As palavras se esgotam - e se nada mais há a dizer, então resta o silêncio. Resta o homem - só. Resta a vida. Monica Vitti dá seu testemunho de atriz:

Antes de dizer "Corta!", quando a fala terminou, o diálogo terminou, há um momento de desorientação para um ator, uma passagem. Há uma coisa muito sutil. Há uma passagem entre a vida e a profissão. Ele [Antonioni] se aproveitava desse momento. Ele não dizia logo "Corta!" (A AVENTURA, 1960, bônus).

O corte se prolonga: o diálogo terminou, a fala terminou, mas a tomada não termina - o momento continua. Resta citar mais um personagem no que tange ao tempo morto de Antonioni: Roland Barthes. Para este, há uma natureza politicamente subversiva desse traço estilístico: "Ele é perigoso, pois olhar mais tempo do que é requerido [...] incomoda todas as ordens estabelecidas, quaisquer que sejam, na medida em que, normalmente, o próprio tempo do olhar é controlado pela sociedade" (BARTHES apud CHAPMAN; DUNCAN, 2008, p.33).

Tempo morto: nada mais a dizer, e a vida segue. Os filmes de Antonioni são surpreendentes, como a vida: os acasos se sucedem. Antonioni confirma essa nossa intuição: "A cadência de 'A Aventura'... muitos acharam muito lenta, aborrecida, tediosa mesmo. Acho que é a própria cadência da vida. Há coisas que se precipitam, outras que ficam imóveis" (A NOITE, 1961, bônus). É fato que, lisonjeiro ou não, Antonioni já foi chamado de "poeta do tédio": nada se passa, nada se diz (OLIVEIRA, 2008, p.2). E seu sucesso também se deve à sua capacidade de criar esse "tédio". Como explicam Chatman e Duncan:

A partir de "A Aventura", Antonioni atribui a seus personagens uma panóplia de traços de personalidade sugerida de maneira indireta, quase unicamente por meio de sua aparência exterior - expressão do rosto, postura corporal, posição no cenário -, e não por diálogos ex- 
plicativos. Além disso, os diálogos servem mais para mascarar o pensamento e os sentimentos dos personagens, de modo que as palavras são geralmente antípodas de suas preocupações e situações imediatas (CHATMAN; DUNCAN, 2008, p.37).

Assim, o que resta é o silêncio: não há qualquer explicação verbal. Em vez de seus personagens se exprimirem por palavras, Antonioni prefere as imagens mas mesmo o que vemos não nos é facilmente determinável. Seus personagens não falam o que sentem; então, o que vemos é resultado de todo o ritmo do próprio filme, o que nos faz crer que sejam personagens entediados, eternamente insatisfeitos.

Agora é preciso dizer que se é comum chamar o Wittgenstein do "Tractatus" de "primeiro" é porque há (pelo menos) um segundo: o das "Investigações Filosóficas". Nesse segundo momento de seu pensamento sobre a linguagem, alguns de seus principais comentadores entendem que o incomunicável desaparece em Wittgenstein. Se em seu primeiro pensamento haveria uma diferença entre aquilo que pode ser dito e aquilo que deve ser calado (logo, que só pode ser mostrado), no Wittgenstein das "Investigações Filosóficas" tudo que pode ser compreendido pode ser expresso pela linguagem verbal. A linguagem não é apenas um instrumento para denotar coisas do mundo, para representar fatos do real - a linguagem é uma prática humana; a linguagem é uma forma de vida.

Nas "Investigações Filosóficas", então, ao contrário daquilo que o lógico Wittgenstein promulgou no "Tractatus", de que havia uma linguagem lógica por detrás da linguagem comum; uma linguagem lógica a ser descoberta por uma análise também lógica que espelhasse o mundo, este segundo Wittgenstein vai dizer que nada está oculto, ou seja, não há uma linguagem lógica a ser descoberta a partir da linguagem ordinária. A linguagem lógica é uma invenção do homem - a linguagem, dessa forma, já é essa que está aí: como a nossa vida é esta que está aqui:

Você deve ter em atenção que o jogo de linguagem é, por assim dizer, imprevisível. Quero dizer: não se baseia em fundamentos. Não é razoável (ou irrazoável). Está aí - tal como a nossa vida (WITTGENTEIN, 1998 , § 559).

O significado linguístico, igualmente, não se dá a ver por qualquer análise lógica que faz uma operação metafísica de separar a linguagem do mundo. A linguagem só existe no mundo - linguagem e mundo se constituem mutuamente. Por isso, nada está oculto - tudo já está diante de nossos olhos. Por isso, a linguagem é uma forma de vida.

Podemos completar: como as imagens de Antonioni, em que o diretor mostra a vida que segue. Como o próprio Antonioni disse em entrevista: "Mesmo nos detalhes que escolhi para cada plano, cada cena, cada sequência, tentei achar coisas que são as que vejo" (A NOITE, 1961, bônus). Seus planos-sequência, sua câmera, mostram a condição humana - e como agimos neste mundo, pois não há como operar um voo para fora dele. 
Ao mesmo tempo, na mesma proporção que as imagens de Antonioni mostram, os sentidos se expandem. Como observa o já citado escritor e diretor Alain Robbe-Grillet, o cinema de Antonioni seria o oposto dos filmes de Hitchcock, pois, ao contrário deste, Antonioni nada esconde, ele é a antítese do suspense. Contudo, se os filmes de Hitchcock, à medida que a trama se desenrola, mais vão se fechando para um sentido final, para um fecho que responde ao desejo do espectador por uma resposta que dê sentido a tudo que havia ficado oculto até ali, Antonioni revela este grande traço da Modernidade: seus filmes vão caminhando gradualmente para uma abertura de sentidos, isto é, à medida que a narrativa avança, menos o fecho se fecha. Como disse o já mencionado Barthes em seu discurso sob forma de carta aberta intitulada "Cher Antonioni" pronunciada em 28 de janeiro de 1980 quando da cerimônia da entrega do Archinnasio d'oro pela cidade de Bolonha, dirigindo-se ao cineasta: "porque você é um artista que sua obra é aberta ao Moderno [...] Sua arte consiste a sempre deixar a rota do sentido aberta", de modo que a significação de seus filmes residem "na própria incerteza do sentido" (BARTHES, 1980, p.1-2).

Isso explica em parte por que Antonioni foi rotulado como o diretor da incomunicabilidade. Como já disse ao iniciar este meu ensaio, o próprio Antonioni rejeitava tal rótulo. Em dezembro de 1985, no programa de auditório Maurizio Costanzo Show da TV italiana, vemos um Antonioni mal-humorado esbravejar:

A incomunicabilidade... Eu tenho a reputação de ser o diretor da "incomunicabilidade". É algo que sempre me atribuíram. Sempre. Ninguém pensa que se é verdade que existe essa incomunicabilidade de que todos me falaram e todos me atribuíram significa dizer que eu a comuniquei, eu comunico a "incomunicabilidade"; e, portanto, eu não sou incomunicável (MICHELANGELO, 2001, 49:30).

A plateia ri; a plateia aplaude - porque a "incomunicabilidade" Ihe parece algo impossível, risível. Afinal, se a "incomunicabilidade" não pode ser comunicada, e se tudo é comunicável, tal "reputação" imposta ao diretor não faz sentido. Antonioni comunica isso: ele sempre comunica - de modo que a conclusão óbvia é que ele não pode ser incomunicável.

Porém, a tese possível a se propor é que, wittgensteinianamente, se nada mais está oculto, assim como não existe um incomunicável para além do que sempre comunicamos, então o incomunicável está aqui, também diante de nossos olhos. Então, a trilogia da incomunicabilidade não é assim nomeada porque não comunica, mas porque seus personagens não se comunicam - porque eles poderiam dizer uns para os outros, se os diálogos dos filmes de Antonioni fossem "explicativos", como em narrativas clássicas, por exemplo, em que são poucos os espaços deixados para darmos sentido, coisas como: "A gente não está se entendendo", "Não foi isso que eu quis dizer", "Você não me entende, é tudo". Num certo sentido, pode-se dizer que esses possíveis gestos metalinguísticos são compreensíveis e comunicam uma experiência (pragmática?) do inefável. Se não há uma linguagem para além desta, então também experimentar a incomunicabilidade só pode acontecer aqui. 
Assim, não é por acaso que se fala em tetralogia da incomunicabilidade porque nos quatro filmes incomoda isto: a falta de comunicação entre as personagens. Ao mesmo tempo, nos quatro filmes nos surpreende isto: a compreensão do mundo que conhecemos, agora, por causa dessa incomunicabilidade. Ao mesmo tempo, assistir à Tetralogia da Incomunicabilidade, então, é também experimentar certa aflição: porque, ao fim e ao cabo, é a falta de comunicação o que prevalece entre os casais - é "o normal", o padrão das relações humanas. Os relacionamentos se dão na falta, no vácuo, no vazio da comunicação.

Assim como soa paradoxal comunicar a incomunicabilidade, fecho meu ensaio deixando em aberto dois paradoxos. O Paradoxo 1: se a língua é alteridade, na medida em que pressupõe o outro, na medida em que só há língua porque há o outro, como poderia haver esse fosso, esse vão em que todo esforço de comunicação resulta em nada - (é) vão? O Paradoxo 1 sitia a ilha: para ser linguagem é preciso não ser de um só, e, no entanto, como me comunicar com o outro? Fadados à vagueza da linguagem, cairíamos num solipsismo, enfurnados entre quatro paredes: linguagem pressupõe o outro e pressupõe o risco de ser mal-entendido pelo outro. Pressupõe o risco do incomunicável (?)

E, então, chegamos ao Paradoxo 2: a incomunicabilidade é "o normal", o padrão - ainda que o "normal" e o padrão seja precisar do outro para haver linguagem? Cartesianamente, a linguagem verbal é tida como o diferencial entre a espécie humana e as demais. Paradoxalmente, se a incomunicabilidade é o padrão, o ser humano, refém de sua incomunicabilidade, estaria desumanizado?

Os filmes/poemas de Antonioni falam da linguagem porque falam da existência humana - e, também por isso, tocam no nervo de nossos instintos que nos faz bicho. Como o próprio Antonioni confirma: "Aquilo que me interessa é o Homem" (MICHELANGELO, 2001, ?). Mas em seus filmes o Homem confronta a si mesmo - e, então, a solidão de ser Homem.

Sim, Antonioni está certo: ele comunicou a incomunicabilidade. Todavia, antes de isso significar um triunfo da comunicação, me parece um reconhecimento do limite da linguagem. Não que haja um fosso para além do Homem - o fosso está no homem.

\section{Referências}

A AVENTURA. Direção: Michelangelo Antonioni. Itália. Continental Home Video. 1960. DVD, 143 min, cor. Título original: L'Avventura

A NOITE. Direção: Michelangelo Antonioni. Itália/França. Continental Home Video. 1961. DVD, 114 min, preto e branco. Título original: La Notte

ANTONIONI - Documentos e testemunhos. Direção: Gianfranco Mingozzi. Canadá/ltália. 1966. 58 min. Título original: Michelangelo Antonioni storia di un autore.

BARTHES, R. Cher Antonioni. 1980. Disponível em:

<http://www.etyen.be/sites/default/files/professeur/r.barthes_cherantonioni.pdf> Acesso em: 30 jun 2016. 
CHATMAN, S; DUNCAN, P. Michelangelo Antonioni: filmographie complète. Paris; Colônia: Taschen, 2008.

DEAR Antonioni. Itália/Inglaterra. RAI e BBC. 1990. Documentário.

MICHELANGELO Antonioni: o olhar que mudou o cinema. Direção: Sandro Lai. Itália. 2001. documentário. 55 min, col/preto e branco. Título original: Lo Sguardo Che Ha Cambiato II Cinema.

O DESERTO vermelho. Direção: Michelangelo Antonioni. Itália. Versatil Home Video. 1964. DVD, 113 min, cor. Título original: II Deserto Rosso

O ECLIPE. Direção: Michelangelo Antonioni. França/Itália. Versatil Home Video. 1962. DVD, 125 min, cor. Título original: L'Eclisse

OLIVEIRA, R. A. de. Cinema italiano: Antonioni e a Trilogia da Incomunicabilidade. 2008. Disponível em: <http://cinemaitalianorao.blogspot.com.br/2008/02/antonioni-e-trilogia-da.html>. Acesso em: 30 jun 2016.

PASOLINI, P. P. Cine de poesía. In: PASOLINI, P. P.; ROHMER, E. Cine de poesía contra cine de prosa. Traducido por Joaquín Jordá. Barcelona: Editorial Anagrama, 1970 [1965]

RIBEIRO, M. Os cem anos do mestre Michelangelo Antonioni.

$<$ http://miltonribeiro.sul21.com.br/tag/michelangelo-antonioni/>

VEJA.com Sai em DVD trilogia de Michelangelo Antonioni. 2012. Disponível em:

<http://veja.abril.com.br/noticia/entretenimento/sai-em-dvd-trilogia-de-michelangelo-antonioni/> Acesso em: 30 jun 2016.

WITTGENSTEIN, L. Tractatus Logico-Philosophicus. Tradução, apresentação e estudo introdutório de Luiz Henrique Lopes dos Santos. Introdução de Bertrand Russell. 3. ed. São Paulo: Ed. da Universidade de São Paulo, 2001.

Da certeza. Lisboa: Edições 70, 1998.

. Investigações Filosóficas. Tradução de José Carlos Bruni. São Paulo: Abril Cultural, 1975.

(Coleção Os Pensadores).

Recebido em : 28/11/2016 - Aprovado em: 30/05/2017 